\title{
Respiratory Therapists' Involvement in End-of-Life Discussions: Stepping Up to the Plate
}

Many respiratory therapists (RTs) currently work in the ICU or have worked in the ICU at some point in their careers. RTs care for a great number of patients at various stages of their lives with varying outcomes. In the United States, approximately one in 5 people die in the ICU. ${ }^{1}$ It is logical to conclude that RTs should be involved in the end-of-life discussions among the care team and patient-family unit.

Several research teams have explored the concepts of end-of-life care and the involvement of multidisciplinary care teams. The literature recommends effective communication among the care team as well as between the care team and the patient-family unit, cross-cultural sensitivity, coordination of care, and the integration of palliative care in the ICU. ${ }^{1-4}$ However, the ability of the care team to provide these key components of end-of-life care depends upon the educational foundation and competency of the care team members, regardless of discipline.

Although entry-to-practice RT curriculum standards do not mandate coursework or experience in ethical decision making, end-of-life care, withdrawal of life support, or palliative care, ${ }^{5}$ the entry-level board examination does include withdrawal of life support on the exam matrix, ${ }^{6}$ and many educational programs attempt to integrate these concepts into the didactic and clinical coursework. However, the findings of the study by Grandhige et $\mathrm{al}^{7}$ in this issue of RESPIRATORY CARE support prior findings ${ }^{8,9}$ that respiratory therapists do not feel adequately prepared to participate in end-of-life discussions; nor are they frequently involved in these discussions. Indeed, their findings indicate that there is a disconnect between the terminal weaning decision-making process and the act of discontinuing mechanical ventilation (ie, terminal extubation).

The researchers' objective was to "understand the experiences of RTs as it relates to performing terminal extubations, including whether and how they were included in the decision-making process and the degree to which they communicated with families about the process of re-

\footnotetext{
Dr Strickland has disclosed no conflicts of interest.
}

Correspondence: Shawna L Strickland PhD RRT-NPS RRT-ACCS AE-C FAARC, 9425 N MacArthur Blvd Suite 100, Irving, TX 75063. E-mail: shawna.strickland@aarc.org.

DOI: $10.4187 /$ respcare.04909 moval." "This study discovered that, although the majority of the sample (93.8\%) have participated in a terminal extubation, very few speak directly with the patient and/or

See the Original Study on Page 891

family about end-of-life care (12.3\%), are part of the multidisciplinary team that discusses end-of-life care (10.8\%), or are comfortable with end-of-life discussions with the patient and/or family (29.2\%). The study also identified that only about one third of RTs have received formal education and/or post-graduate education regarding terminal illness, but over half of those studied would like to have formal education and support regarding the care of terminal patients. These results are similar to the results discovered by prior research ${ }^{8,9}$ and highlight that this continues to be an area of improvement for RTs.

As the role of the RT continues to expand, accompanying competencies will expand as well. Integrating content regarding ethical decision-making, end-of-life care, withdrawal of life support, and palliative care not only into the entry-to-practice formal curriculum but also into postgraduate continuing education for RTs is vital to improving the RT's ability to participate and contribute to higher quality care for the patient at the end of life. RT integration into care teams focused on palliative care and end-of-life care as well as into primary care teams in the ICU will not only enhance collaboration but also improve patient care.

Shawna L Strickland PhD RRT-NPS RRT-ACCS AE-C FAARC American Association for Respiratory Care Irving, Texas

\section{REFERENCES}

1. Curtis JR. Caring for patients with critical illness and their families: the value of the integrated clinical team. Respir Care 2008;53(4):480-487.

2. Truog RD, Campbell ML, Curtis JR, Haas CE, Luce JM, Rubenfeld $\mathrm{GD}$, et al. Recommendations for end-of-life care in the intensive care unit: a consensus statement by the American College of Critical Care Medicine. Crit Care Med 2008;36(3):953-963.

3. Lorenz KA, Lynn J, Dy SM, Shugarman LR, Wilkinson A, Mularski RA, et al. Evidence for improving palliative care at the end of life: a systematic review. Ann Int Med 2008;148(2):147-159. 


\section{EDITORIALS}

4. Lanken PN, Terry PB, Delisser HM, Fahy BF, Hansen-Flaschen J, Heffner JE, et al. An official American Thoracic Society clinical policy statement: palliative care for patients with respiratory diseases and critical illnesses. Am J Respir Crit Care Med 2008;177(8):912-927.

5. Accreditation standards for entry into respiratory care professional practice. Commission on Accreditation for Respiratory Care. http://www.coarc.com/uploaded/files/CoARC\%20Entry\%20Standards \%20clarif\%2011.21.15.pdf. 2015.

6. Therapist multiple-choice examination detailed content outline. National Board for Respiratory Care. https://www.nbrc.org/Documents/ TMC\%20Detailed\%20Content\%20Outline.pdf. 2015.
7. Grandhige AP, Timmer M, O’Neil M, Binney ZO, Quest TE. Respiratory therapists' experiences and attitudes regarding terminal extubations and end-of-life care. Respir Care 2016;61(7):891896.

8. Brown-Saltzman K, Upadhya D, Larner L, Wenger NS. An intervention to improve respiratory therapists' comfort with end-of-life care. Respir Care 2010;55(7):858-865.

9. Willms DC, Brewer JA. Survey of respiratory therapists' attitudes and concerns regarding terminal extubation. Respir Care 2005;50(8): 1046-1049. 